\title{
The effects of hyperbaric oxygen therapy (HBOT) on coronavirus disease-2019 (COVID-19): a systematic review
}

\author{
Shahram Oliaei ${ }^{1}$, SeyedAhmad SeyedAlinaghi ${ }^{2}$, Mohammad Mehrtak ${ }^{3}$, Amirali Karimi ${ }^{4}$, Tayebeh Noori ${ }^{5}$, \\ Pegah Mirzapour ${ }^{2}$, Alireza Shojaei ${ }^{2}$, Mehrzad MohsseniPour ${ }^{2}$, Seyed Peyman Mirghaderi ${ }^{4}$, Sanam Alilou ${ }^{4}$, \\ Parnian Shobeiri ${ }^{4}$, Hadiseh Azadi Cheshmekabodi ${ }^{6}$, Esmaeil Mehraeen ${ }^{7,8^{*}} \mathbb{0}$ and Omid Dadras ${ }^{9}$
}

\begin{abstract}
Background: Oxygenation serves as a cornerstone in the treatment of COVID-19, and several methods have been extensively studied so far. Herein, we aimed to systematically review the studies discussing hyperbaric oxygen therapy (HBOT) to examine its reported efficacy and adverse events in patients with COVID-19.

Methods: We systematically searched and retrieved the relevant articles using keywords on the online databases, including PubMed, Scopus, Embase, Web of Science, and Cochrane databases up to April 11th, 2021. The retrieved records underwent a two-step title/abstract and full-text screening process, and the eligible papers were identified. National Institutes of health $(\mathrm{NIH})$ quality assessment tool was used for this study. This study was registered in the International Prospective Register of Systematic Reviews (PROSPERO) with ID CRD42021269821.

Results: Eight articles from three countries were included. All the included studies had good and fair quality scores, with no poor studies included in this systematic review (Good: $n=5$, Fair: $n=3$ ). Studies were divided into clinical trials and case reports/series. Most of the studies used HBOT less than 1.5-2 absolute atmospheres (ATA) for 90 min sessions and thereafter sessions were decreased to $60 \mathrm{~min}$. Trials demonstrated most of the patients recovered after receiving $\mathrm{HBOT}$, and blood oxygen saturation increased after several sessions of HBOT.
\end{abstract}

Conclusion: Overall, HBOT seems to be a safe and effective oxygenation method in patients with COVID-19. However, there is limited knowledge and evidence regarding the effects and mechanism of HBOT in COVID-19 treatment, and further evaluations require extensive well-designed studies.

Keywords: COVID-19, Hyperbaric oxygenation, Hyperbaric oxygen therapy, SARS-CoV-2

\section{Background}

COVID-19 is an acute respiratory infection caused by the SARS-CoV-2; it emerged as a novel human pathogen in China at the end of 2019 continues to be a pandemic worldwide [1-4]. The most common manifestations are

*Correspondence: es.mehraeen@gmail.com

${ }^{8}$ Department of Health Information Technology, Khalkhal University of Medical Sciences, 1419733141 Khalkhal, Iran

Full list of author information is available at the end of the article pneumonia, high fever, myalgia, dry cough, and chest pain [5-9]. The death rate due to COVID-19 varies from $1 \%$ to more than $7 \%$, and respiratory failure is the main cause $[10,11]$. Research is underway to identify and evaluate the effectiveness and safety of interventions to treat the patients with COVID-19 based on their disease severity $[12,13]$.

Approximately, 15-20\% of hospitalized patients present with hypoxemic respiratory failure, accompanied by the need for oxygen supplementation [14]. Hyperbaric original author(s) and the source, provide a link to the Creative Commons licence, and indicate if changes were made. The images or other third party material in this article are included in the article's Creative Commons licence, unless indicated otherwise in a credit line to the material. If material is not included in the article's Creative Commons licence and your intended use is not permitted by statutory regulation or exceeds the permitted use, you will need to obtain permission directly from the copyright holder. To view a copy of this licence, visit http://creativecommons.org/licenses/by/4.0/. The Creative Commons Public Domain Dedication waiver (http://creativeco mmons.org/publicdomain/zero/1.0/) applies to the data made available in this article, unless otherwise stated in a credit line to the data. 
oxygen therapy (HBOT) has been proposed as an alternative therapeutic approach to address COVID-19-associated hypoxia $[12,15]$. HBOT is recognized as an effective treatment for replacing any form of oxygen deficiency [14]. HBOT is a non-invasive treatment and serves as primary or adjunctive therapy in various medical conditions [16]. The efficacy of HBOT has been documented in several systemic illnesses, such as arterial gas embolism, carbon monoxide poisoning, decompression sickness, crush injuries, and diabetic foot ulcer [17].

HBOT involves intermittently using high concentration oxygen $(100 \%)$ in an environmental pressure higher than one absolute atmosphere (atm) inside a chamber to enhance the amount of oxygen dissolved in the body's tissues $[18,19]$. HBOT can increase the circulation and delivery of oxygen under high pressure, making the tissue uptake more efficient and improve hypoxia in COVID-19 patients [17]. In addition, hyperoxygenation of arterial blood with plasma-dissolved oxygen during HBOT has a strong anti-inflammatory effect and may have a direct virucidal impact on COVID-19 [20]. Preliminary clinical evidence of HBOT treatment in hypoxemic COVID-19 patients demonstrated clinical improvement, e.g., reduce ICU admission and prevent transition to mechanical ventilation $[15,21]$.

HBOT is regarded as a safe and low-risk intervention [22]. There are no contraindication to the use of HBOT in patients with viral, bacterial or fungal infections [23]. The only major contraindications to HBOT are untreated pneumothorax and respiratory failure requiring mechanical ventilation [20]. Recent studies pointed out that HBOT could be a decisive treatment for improving outcomes in patients with COVID-19 pneumonia, especially at early stages, and it could also be beneficial during the intubation period [17]. The objective of this study is to review and discuss the efficacy and adverse events of HBOT in patients with COVID-19.

\section{Methods \\ Design}

We systematically searched and retrieved the relevant articles using keywords on the online databases, including PubMed, Scopus, Embase, Web of Science, and Cochrane databases up to April 11th, 2021. We reviewed the retrieved articles and removed the duplicates. The remaining records underwent a two-step screening process. First, a researcher (A.S.) screened the records based on their title/abstract, and irrelevant records were excluded. Then, A.S. examined the full-text of the remaining documents based on their cohesion to inclusion criteria, and the eligible studies were identified. Another researcher (A.K.) addressed any uncertainty during the review process. This study was registered in the International Prospective Register of Systematic Reviews (PROSPERO) with ID CRD42021269821.

\section{Search strategy}

We performed a systematic search on the online databases using the keywords such as "Hyperbaric oxygen therapy" and "COVID-19".

\section{Inclusion/exclusion criteria}

We included all articles, including case reports, case series, clinical trials, cross-sectional, case-control, and cohort studies investigating the effect of HBOT on COVID-19 outcomes; and therefore, the exclusion criteria were as follows:

1. Non-original studies, including review articles, metaanalyses, and non-original editorials

2. Unavailability of full texts and abstracts/conference abstracts

3. Ongoing clinical trials with unpublished results.

\section{Data acquisition}

A researcher designed the data extraction table. Three other researchers extracted the data related to the patients' characteristics, country of origin, clinical manifestation, laboratory findings, time/pressure/duration of HBOT, patients' outcome were extracted and included in the abovementioned table. Another researcher checked the data and addressed the controversies.

\section{Quality assessment}

We utilized the National Institutes of Health (NIH) quality assessment tool [24] to evaluate the included studies. We used the scores of $7-9,4-6$, and $0-3$ to represent good, fair, and poor ratings for the case series and case reports. For cross-sectional cohort and controlled interventional studies, $11-14,6-10$, and $0-5$ were utilized, respectively. We chose the scores of $9-12,5-8$, and $0-4$ for case-controls (Table 1).

\section{Results}

We systematically searched the databases mentioned above, and this search yielded 143 results. Of these, 56 were duplicate records. Of the remaining, 64 were removed in the title/abstract screening, and 25 articles entered the full-text screening process, of which 8 articles were finally met the eligibility criteria and included in this review. Figure 1 illustrates the details of the selection process. Three studies were clinical trials, and the other five studies were either case series or case reports. These eight studies are from three countries of China, USA, and Russia. 
Table 1 Applying the NIH quality assessment tool for all the included studies

\begin{tabular}{|c|c|c|c|c|c|}
\hline Study & Total score & $\begin{array}{l}\text { Quality rating (good, fair, } \\
\text { or poor) }\end{array}$ & Study & Total score & $\begin{array}{l}\text { Quality rating } \\
\text { (good, fair, or } \\
\text { poor) }\end{array}$ \\
\hline \multicolumn{6}{|c|}{ Controlled interventional studies (score out of 14) } \\
\hline Gorenstein, S. A & 11 & Good & Petrikov, S.S & 8 & Good \\
\hline Levina, O. A & 10 & Fair & & & \\
\hline \multicolumn{6}{|c|}{ Case series and case reports (score out of 9) } \\
\hline Chen, R. Y & 6 & Fair & Guo, D. Z & 6 & Fair \\
\hline Liang, $Y$ & 7 & Good & Thibodeaux, K & 7 & Good \\
\hline Xiao-Ling, Z & 7 & Good & & & \\
\hline
\end{tabular}


Studies included in qualitative synthesis $(\mathrm{n}=8)$

Fig. 1 PRISMA flow diagram of the study selection process

All the included studies had good and fair quality scores. No poor quality study was included in this review (Good: $n=5$, Fair: $n=3$ ) (Table 1). Studies were conducted in different countries, including Russia, China, and USA. Studies were divided into clinical trials and case series. Eight studies were supporting the use of HBOT in patients infected with SARS-CoV-2. Trials showed most of the patients recovered after receiving HBOT, and blood oxygen saturation increased after several sessions of HBOT. Although one study did not support the hypothesis of the present review, other studies suggested that HBOT could be an effective measure to correct the hypoxemia induced by COVID-19 (Table 2). Of the studies, 3 clinical trials were trying to show the efficacy of the HBOT on patients infected with COVID-19. The results indicated a significant effect of HBOT on patients, and it 


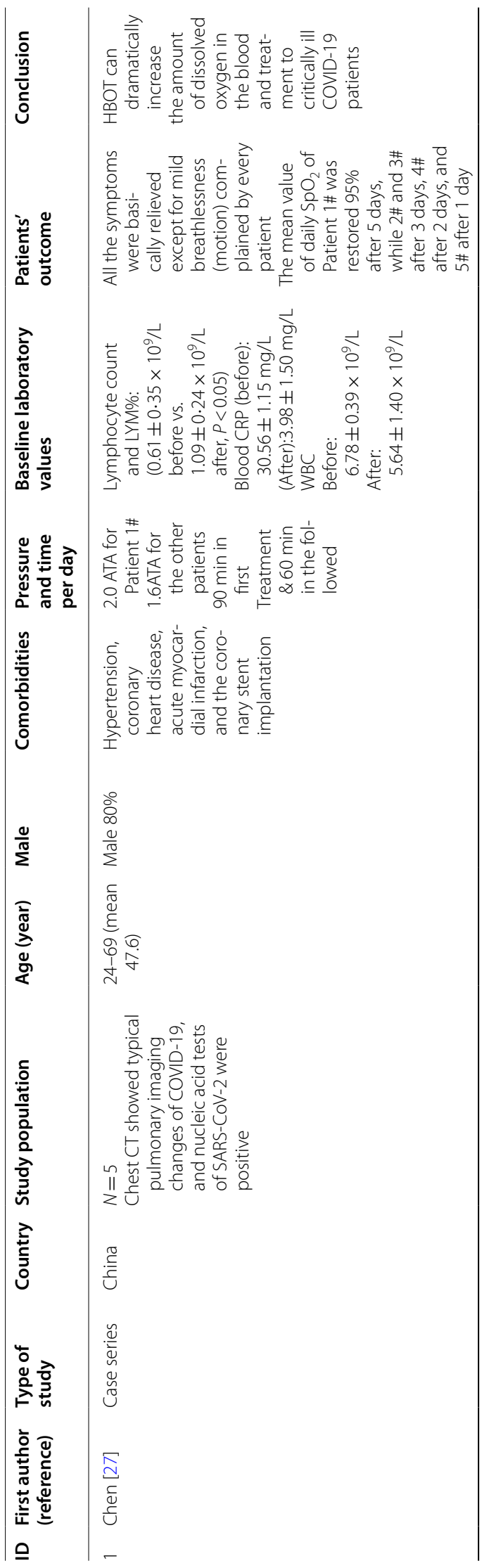




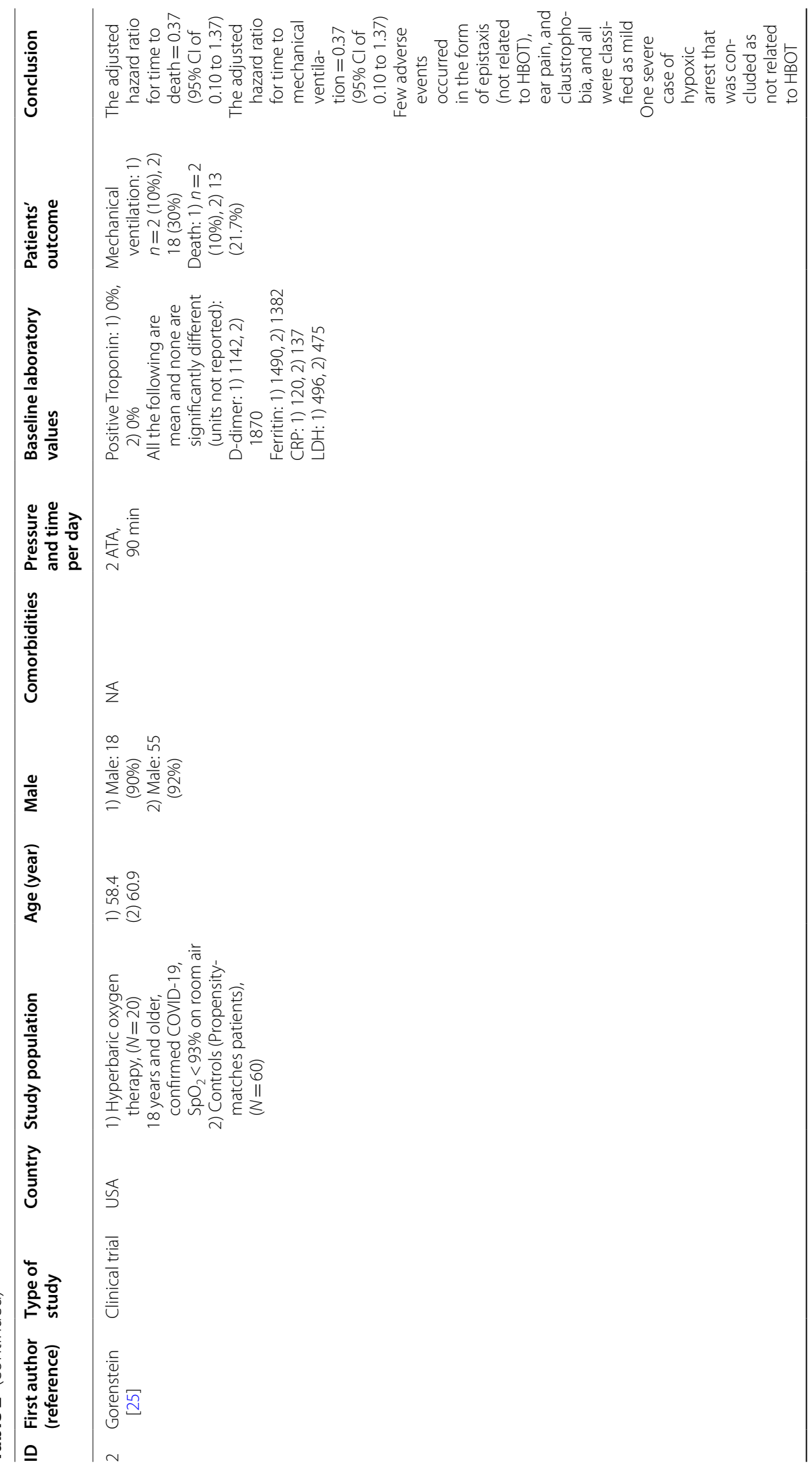




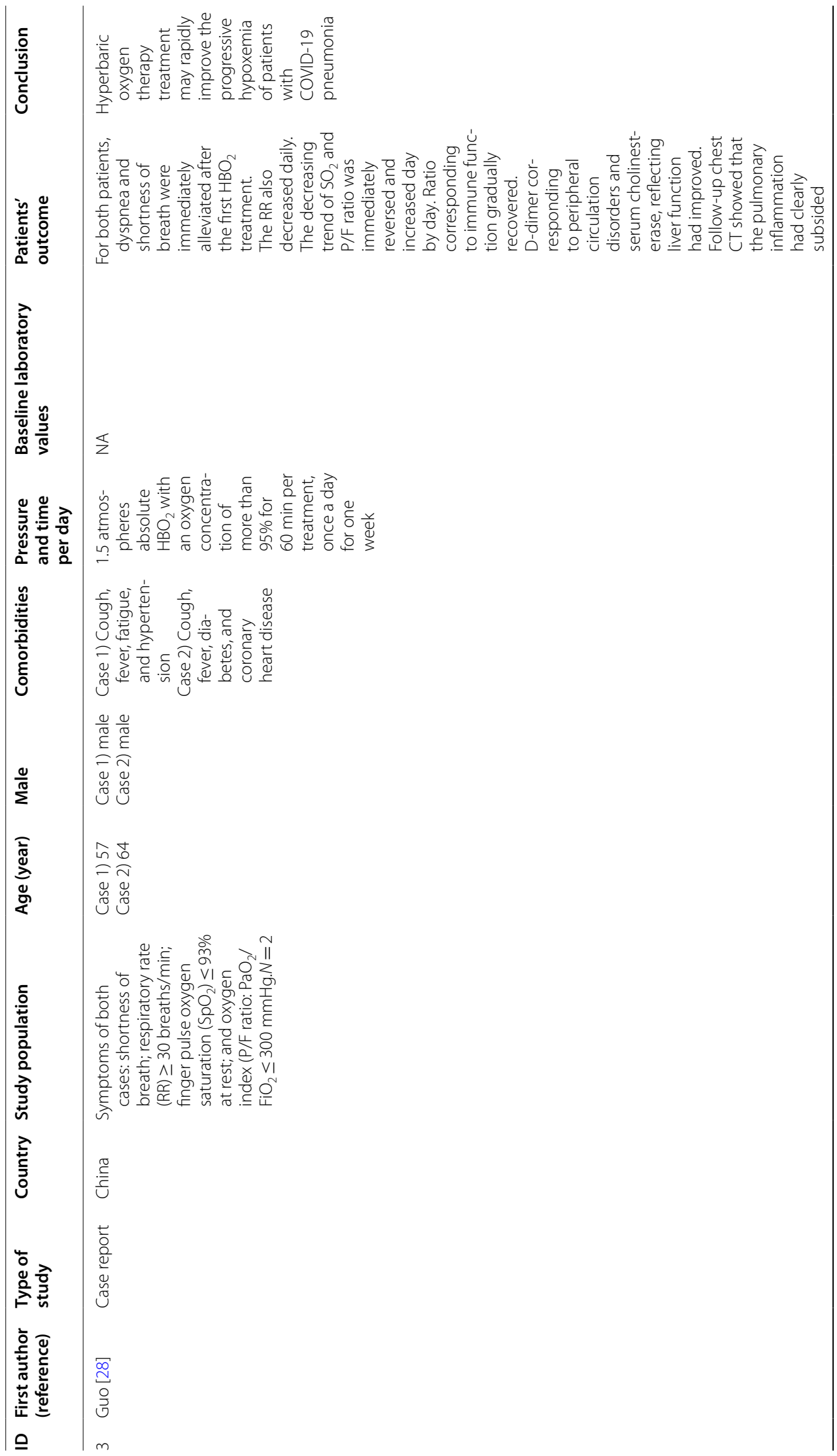




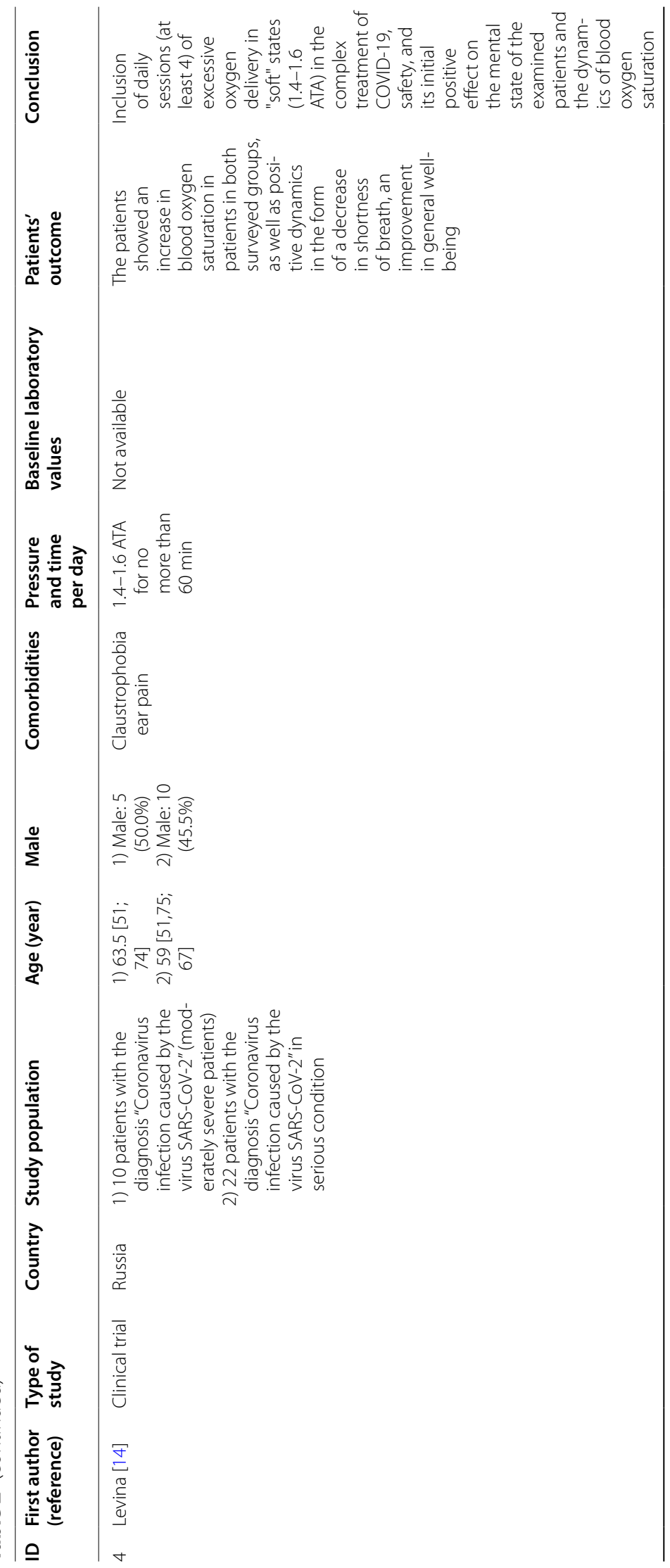




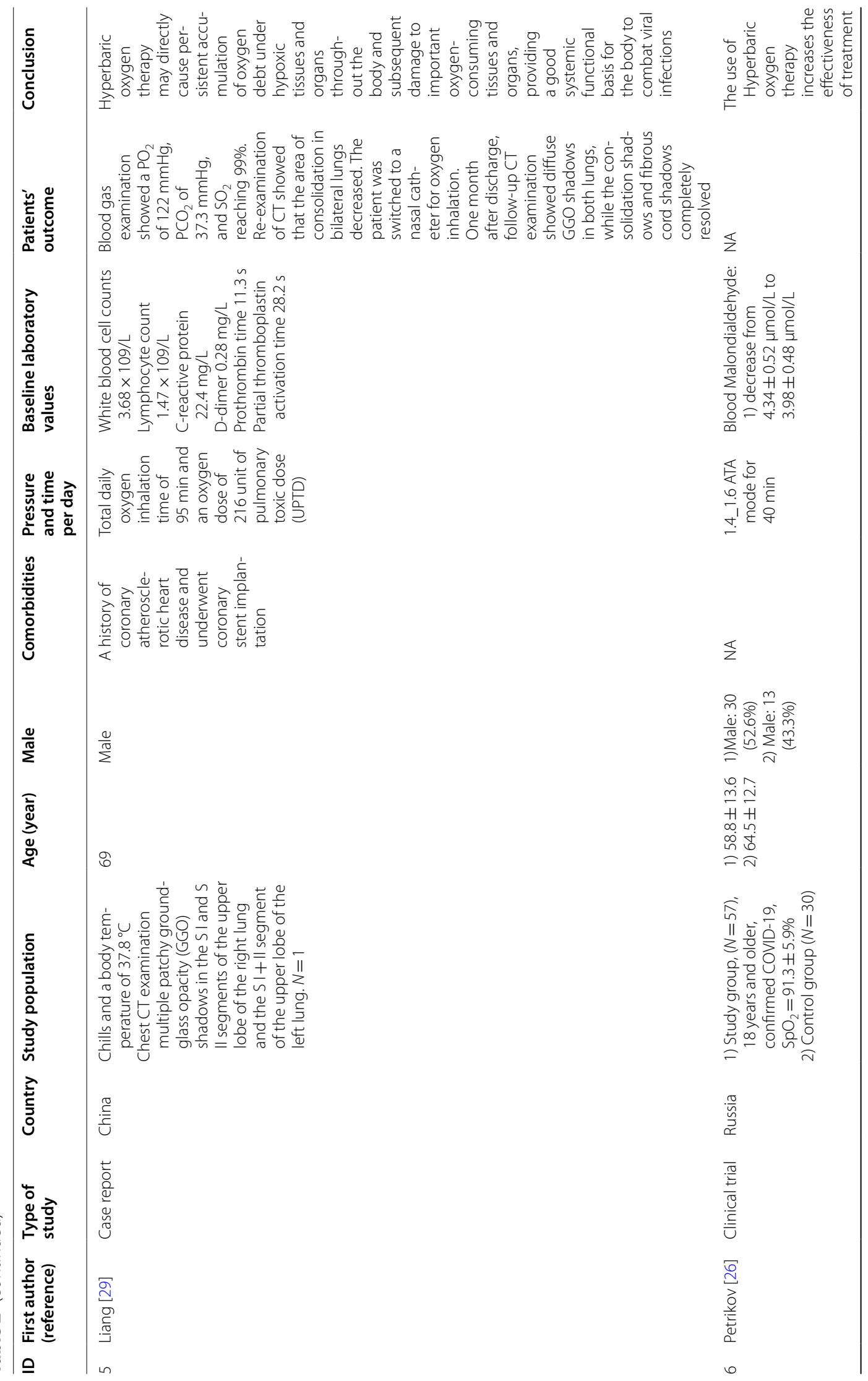




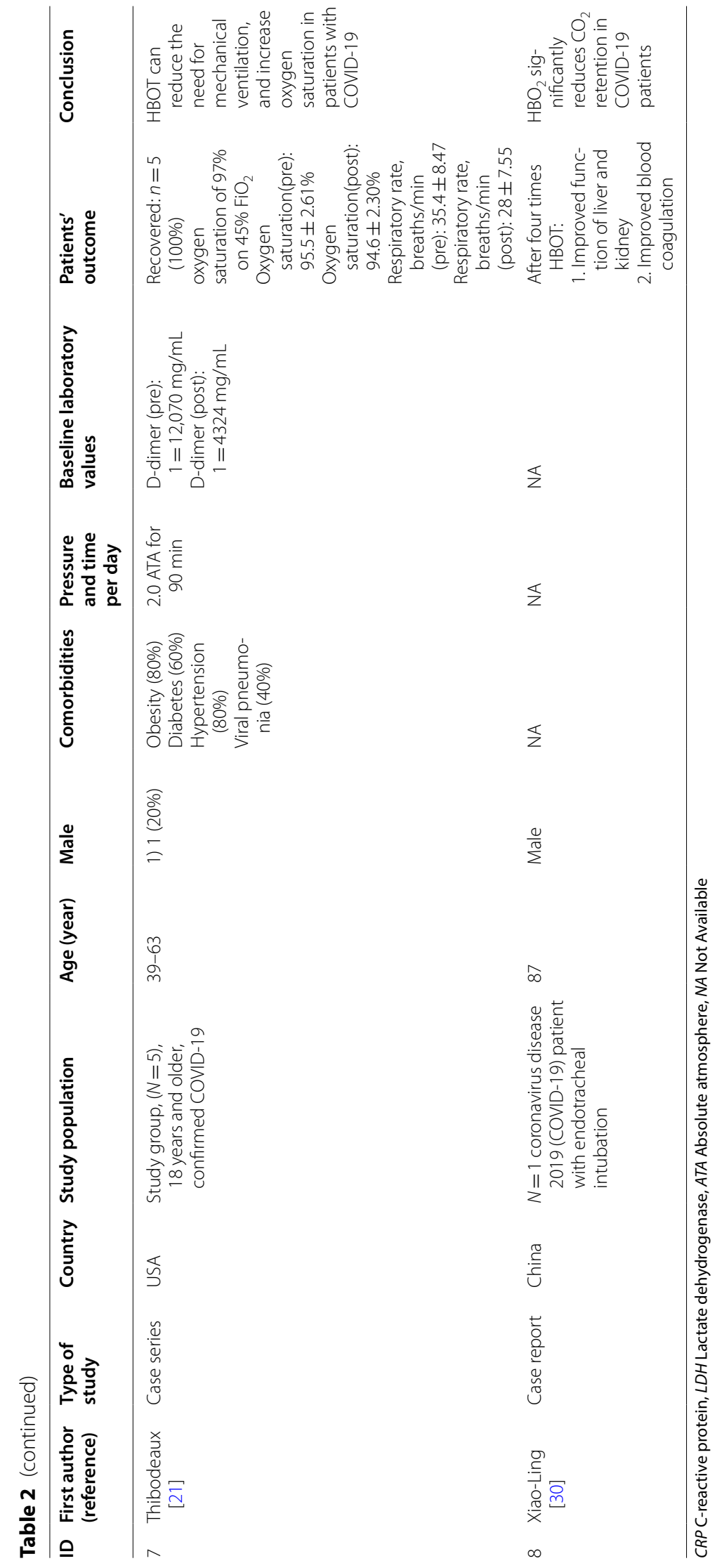


was safe and beneficial for them to breathe $100 \%$ oxygen $[14,25,26]$. Treatment adverse events were very limited and Gorenstein et al. reported mild epistaxis not related to HBOT, ear pain, and claustrophobia [25], but the studies are few and lack large groups of patients, and therefore, adverse events should be further studied in larger clinical trials.

\section{Discussion}

Aggressive oxygen therapy is a mainstay treatment for critically ill COVID-19 patients and has been used in various methods to reduce mortality [31]. For severe COVID-19 patients with acute hypoxemic respiratory failure, in addition to conventional oxygen therapy, the National Institutes of Health (NIH) guideline [32] suggests high-flow nasal cannula (HFNC) oxygen for the treatment as the first choice. As a second choice, noninvasive positive pressure ventilation (NIPPV) could be applied under close monitoring. Further refractory hypoxemia necessitates endotracheal intubation in these patients. At last, extracorporeal membrane oxygenation (ECMO), however, with inconclusive evidence, could potentially use as rescue therapy for patients with severe acute respiratory distress syndrome (ARDS) [33, 34]. The whole aim of extra oxygenation is to reach $\mathrm{O}_{2}$ saturation of 92-96\% [32, 35-37], which is attained in some studies included in this review $[14,21,26,27,38]$. HBOT, regardless of the promising evidence on respiratory improvement, has not yet been recommended in the guidelines for severe COVID-19 patients.

HBOT benefits patients by intensifying the oxygen pressure in the alveoli. Consequently, the diffusion rate and the diffusion instance of oxygen will increase compared to standard oxygen therapy (e.g., face mask, invasive ventilation, non-invasive ventilation, nasal cannula, and ECMO) [39]. HBOT provides tissue perfusion exchange capacity due to the increased diffusion instance of oxygen, distinguishing HBOT from all other oxygen therapy methods. Patients treated with HBOT showed improvements in their clinical factors and indexes as follows: (1) arterial blood gas analysis, (2) liver function tests, (3) complete blood count (CBC, diff), and (4) improvement of lung structure clearance based on computed tomography (CT-scan) [39].

It should be noted that COVID-19 patients in hyperbaric chambers need special monitoring and considerations. Briefly, electrocardiogram, pulse oximetry, and temperature monitoring are the backbones of monitoring these patients. The risk of fire accidents increases as high-pressure oxygen is used in a chamber consisting of automated external defibrillator (AED) paddles and external defibrillators; thus, fire prevention should be considered. The ICU personnel should consistently check the endotracheal tube cuff pressure in an intubated patient. Last but not least, as a general rule, personal protective equipment (PPE) must be a priority for health workers caring for such patients [39].

HBOT is currently indicated in conditions such as gas embolism, $\mathrm{CO}_{2}$ and cyanide poisoning, severe anemia, and other pathologic situations [40]. In the HBOT, patients breathe $100 \%$ pure oxygen with high pressure. It may have a beneficial effect in all stages of cell oxygenation, from lung function and alveolar oxygen exchange to the hemoglobin capacity and oxygen delivery to the tissues [27]. In the included studies, we can perceive the merits of HBOT treatments to hypoxemia in critically ill COVID-19 patients. However, further randomized clinical trials with larger sample sizes are necessary to attain compelling evidence to establish HBOT as an effective treatment option in guidelines.

All of the included studies showed promising outcomes in COVID-19 patients who underwent HBOT. This type of oxygen delivery resolved severe COVID19 symptoms and boosted the general well-being of treated patients, along with correcting hypoxia and elevating $\mathrm{O}_{2}$ saturation. While in all manuscripts, $\mathrm{HBOT}$ reduced mortality, only one clinical trial reported a mortality rate of $10 \%$ ( 2 out of 20 ) in COVID-19 patients undergoing HBOT vs. $22 \%$ of that in controls [25]. No death was reported in the rest of the studies; this may be due to the limited study population size and study design, highlighting the need for further clinical trials with larger sample sizes to justify this treatment's potential benefits and side effects.

HBOT remains one of the most effective and safest interventions to compensate for oxygen deprivation in acute respiratory distress syndrome (ARDS) [17]. Since patients breathe naturally in HBOT chambers, they would probably not experience any serious side effects during major respiratory interventions such as mechanical ventilation. Complications such as middle ear and pulmonary barotrauma, oxygen toxicity (mainly involving central nervous system), and ocular effects were reported in previous studies using HBOT for other health issues, with applied pressure mostly exceeding 2.0 ATA [41]. However, some of these adverse effects were not documented in the included studies in this review, probably due to the maximum of 2 ATA pressure, smaller sample size, and different study designs. Only Gorenstein et al. reported mild cases of epistaxis, ear pain, and claustrophobia [25]. One major shortcoming of HBOT might be the lack of accessibility, as there are even shortages in the availability of standard oxygen delivery and HBOT is probably also less available in many centers. 


\section{Limitations}

Although this study is the first endeavor that systematically explored the effect of HBOT on severe respiratory manifestation in COVID-19 patients, some limitations weaken the strength of retrieved evidence, mainly due to the paucity and the design of the selected studies. Data from case series and case reports face bias due to the absence of a control group and limited population enrolled in the study. In addition, many studies were held on critically ill patients who are refractory to routine oxygen therapy; consequently, the authors cannot generalize these data from our sample to the general population of COVID-19 patients. We attempted to include patients only once in our review, but some case series may represent duplicate data that is shared with another case study included from the same setting. In addition, some articles were not written in English, and therefore, we had difficulty translating to perceive the correct concept of it. Last but not least, HBOT equipment are not available in many centers, and this shortage is also more prominent in the pandemic where the availability of such facilities are facing challenges. Therefore, limited patients have access to this treatment option and the populations studied in this systematic review may not be representative of healthcare facilities.

\section{Conclusion}

Overall, HBOT seems to be a safe and effective method of oxygenation in patients with COVID-19. However, its large space occupation and lack of availability in large numbers may limit its use in the settings of a pandemic where many patients require oxygenation, and this shortcoming needs to be addressed. There is limited knowledge and evidence regarding the effects of HBOT in the settings of COVID-19, and further well-designed trials with larger sample sizes are recommended to carefully assess the outcomes of this treatment modality and compare it with other oxygenation methods.

\section{Acknowledgements}

The present study was conducted in collaboration with Supreme National Defense University, Iranian Institute for Reduction of High-Risk Behaviors, Tehran University of Medical Sciences, and Department of Global Health and Socioepidemiology, Kyoto University.

\section{Authors' contributions}

The conception and design of the study: EM and SO. Acquisition of data: AK, PM, MM, and HAC. Drafting the article: EM, MM, AS, SPM, SA, PS, and TN. Revising it critically for important intellectual content: SS and EM. Final approval of the version to be submitted: EM and OD. All the authors read and approved the final manuscript.

\section{Funding}

This research did not receive any specific grant from funding agencies in the public, commercial, or not-for-profit sectors.
Availability of data and materials

The authors stated that all information provided in this article could be shared.

\section{Declarations}

\section{Ethics approval and consent to participate}

The present study was extracted from the research project entitled "Design, develop and evaluate a comprehensive information registration system for patients in the subsurface, diving and hyperbaric medicine" conducted at Supreme National Defense University in 2020.

\section{Consent to publication}

Not applicable.

\section{Competing interests}

The authors declare that there is no conflict of interest regarding the publication of this manuscript.

\section{Author details}

${ }^{1}$ HBOT Research Center, Golestan Hospital, Islamic Republic of Iran, Navy and AJA Medical University, Tehran, Iran. ${ }^{2}$ Iranian Research Center for HIV/ AIDS, Iranian Institute for Reduction of High Risk Behaviors, Tehran University of Medical Sciences, Tehran, Iran. ${ }^{3}$ Healthcare Services Management, School of Medicine and Allied Medical Sciences, Ardabil University of Medical Sciences, Ardabil, Iran. ${ }^{4}$ School of Medicine, Tehran University of Medical Sciences, Tehran, Iran. ${ }^{5}$ Department of Health Information Technology, Zabol University of Medical Sciences, Zabol, Iran. ${ }^{6}$ Health Information Technology, School of Health Information Management and Information Sciences, Iran University of Medical Sciences, Tehran, Iran. ${ }^{7}$ AMAD Research Institute, Supreme National Defense University, Tehran, Iran. ${ }^{8}$ Department of Health Information Technology, Khalkhal University of Medical Sciences, 1419733141 Khalkhal, Iran. ${ }^{9}$ Department of Global Health and Socioepidemiology, Graduate School of Medicine, Kyoto University, Kyoto, Japan.

Received: 12 June 2021 Accepted: 10 August 2021

Published online: 19 August 2021

\section{References}

1. Okumuş N, Demirtürk N, Çetinkaya RA, Güner R, Avcı IY, Orhan S, et al. Evaluation of the effectiveness and safety of adding ivermectin to treatment in severe COVID-19 patients. BMC Infect Dis. 2021;21(1):411.

2. Geier MR, Geier DA. Respiratory conditions in coronavirus disease 2019 (COVID-19): important considerations regarding novel treatment strategies to reduce mortality. Med Hypotheses. 2020;140:109760.

3. Mehraeen E, Seyed Alinaghi SA, Nowroozi A, Dadras O, Alilou S, Shobeiri $P$, et al. A systematic review of ECG findings in patients with COVID-19. Indian Heart J. 2020;72(6):500-7.

4. Mehraeen E, Behnezhad F, Salehi MA, Noori T, Harandi H, SeyedAlinaghi S. Olfactory and gustatory dysfunctions due to the coronavirus disease (COVID-19): a review of current evidence. Eur Arch Oto-rhino-laryngol. 2021;278(2):307-12.

5. Dadras O, Alinaghi SAS, Karimi A, MohsseniPour M, Barzegary A, Vahedi F, et al. Effects of COVID-19 prevention procedures on other common infections: a systematic review. Eur J Med Res. 2021;26(1):67.

6. Krishnan A, Hamilton JP, Alqahtani SA, Woreta T. A narrative review of coronavirus disease 2019 (COVID-19): clinical, epidemiological characteristics, and systemic manifestations. Intern Emerg Med. 2021;16(4):815-30

7. SeyedAlinaghi S, Abbasian L, Solduzian M, Yazdi NA, Jafari F, Adibimehr A, et al. Predictors of the prolonged recovery period in COVID-19 patients: a cross-sectional study. Eur J Med Res. 2021;26(1):1-10.

8. SeyedAlinaghi S, Afsahi AM, MohsseniPour M, Behnezhad F, Salehi MA, Barzegary A, et al. Late complications of COVID-19; a systematic review of current evidence. Arch Acad Emerg Med. 2021;9(1):e14.

9. Ghiasvand F, Miandoab SZ, Harandi H, Golestan FS, Alinaghi SA. A patient with COVID-19 disease in a referral hospital in Iran: a typical case. Infect Disord Drug Targets (Formerly Current Drug Targets-Infectious Disorders). 2020;20(4):559-62. 
10. Baj J, Karakuła-Juchnowicz H, Teresiński G, Buszewicz G, Ciesielka M, Sitarz E, et al. COVID-19: specific and non-specific clinical manifestations and symptoms: the current state of knowledge. J Clin Med. 2020;9(6):1753.

11. Mehraeen E, Karimi A, Barzegary A, Vahedi F, Afsahi AM, Dadras O, et al. Predictors of mortality in patients with COVID-19-a systematic review. Eur J Integr Med. 2020;40:101226.

12. McFee RB. COVID-19: therapeutics and interventions currently under consideration. Dis Mon. 2020;66(9):101058.

13. SeyedAlinaghi S, Mehrtak M, MohsseniPour M, Mirzapour P, Barzegary A, Habibi P, et al. Genetic susceptibility of COVID-19: a systematic review of current evidence. Eur J Med Res. 2021;26(1):1-12.

14. Levina OA, Evseev AK, Shabanov AK, Kulabukhov VV, Kutrovskaya NY, Goroncharovskaya IV, et al. The safety of hyperbaric oxygen therapy in the treatment of Covid-19. Russian Sklifosovsky J Emerg Med Care. 2020;9(3):314-20.

15. El Hawa AAA, Charipova K, Bekeny JC, Johnson-Arbor KK. The evolving use of hyperbaric oxygen therapy during the COVID-19 pandemic. J Wound Care. 2021;30(Sup2):S8-s11.

16. Hajhosseini B, KuehImann BA, Bonham CA, Kamperman KJ, Gurtner GC. Hyperbaric oxygen therapy: descriptive review of the technology and current application in chronic wounds. Plast Reconstr Surg Glob Open. 2020;8(9):e3136-e.

17. De Maio A, Hightower LE. COVID-19, acute respiratory distress syndrome (ARDS), and hyperbaric oxygen therapy (HBOT): what is the link? Cell Stress Chaperones. 2020;25(5):717-20.

18. Hachmo Y, Hadanny A, Abu Hamed R, Daniel-Kotovsky M, Catalogna M, Fishlev $G$, et al. Hyperbaric oxygen therapy increases telomere length and decreases immunosenescence in isolated blood cells: a prospective trial. Aging (Albany NY). 2020;12(22):22445-56.

19. Oliaei S, Mehrabi N, Noori T, Saeidi S, Mehraeen E, editors. Electronic registry system for diabetic patients undergoing hyperbaric oxygen therapy: determination of common data elements. In: Proceedings of the 12th IADIS international conference e-Health 2020, EH 2020-part of the 14th multi conference on computer science and information systems, MCCSIS 2020; 2020

20. Boet S, Katznelson R, Castellucci LA, Fergusson D, Gonevski M, Clarke H, et al. Protocol for a multicentre randomized controlled trial of normobaric versus hyperbaric oxygen therapy for hypoxemic COVID-19 patients. medRxiv. 2020. https://doi.org/10.1101/2020.07.15.20154609.

21. Thibodeaux K, Speyrer M, Raza A, Yaakov R, Serena TE. Hyperbaric oxygen therapy in preventing mechanical ventilation in COVID-19 patients: a retrospective case series. J Wound Care. 2020;29(Sup5a):S4-s8.

22. Hadanny A, Zubari T, Tamir-Adler L, Bechor Y, Fishlev G, Lang E, et al. Hyperbaric oxygen therapy effects on pulmonary functions: a prospective cohort study. BMC Pulm Med. 2019;19(1):148.

23. Mehraeen E, Najafi Z, Hayati B, Javaherian M, Rahimi S, Dadras O, et al. Current treatments and therapeutic options for COVID-19 patients: a systematic review. Infect Disord Drug Targets. 2021. https://doi.org/10. 2174/1871526521666210726150435.

24. SeyedAlinaghi S, Karimi A, MohsseniPour M, Barzegary A, Mirghaderi SP, Fakhfouri A, et al. The clinical outcomes of COVID-19 in HIV-positive patients: a systematic review of current evidence. Immun Inflamm Dis. 2021. https://doi.org/10.1002/iid3.497.

25. Gorenstein SA, Castellano ML, Slone ES, Gillette B, Liu H, Alsamarraie C, et al. Hyperbaric oxygen therapy for COVID-19 patients with respiratory distress: treated cases versus propensity-matched controls. Undersea Hyperb Med. 2020;47(3):405-13.

26. Petrikov SS, Evseev AK, Levina OA, Shabanov AK, Kulabukhov VV, Kutrovskaya NY, et al. Hyperbaric oxygen therapy in patients with COVID-19. Obshchaya Reanimatol. 2020;16(6):4-18.
27. Chen R, Zhong X, Tang Y, Liang Y, Li B, Tao X, et al. The outcomes of hyperbaric oxygen therapy to severe and critically ill patients with COVID-19 pneumonia. https://oxycamaras.com.br/wp-content/uploads/2020/04/ Outcome-of-HBOT-to-COVID19.pdf. Back to cited text. 2020(7). Accessed 20 Sept 2020

28. Guo D, Pan S, Wang M, Guo Y. Hyperbaric oxygen therapy may be effective to improve hypoxemia in patients with severe COVID-2019 pneumonia: two case reports. Undersea Hyperb Med. 2020;47(2):181-7.

29. Liang $Y$, Fan N, Zhong $X$, Fan W. A case report of a patient with severe type of coronavirus disease 2019 (COVID-19) treated by hyperbaric oxygen: CT dynamic changes. Iran J Radiol. 2020;17(4):e104475.

30. Xiao-Ling Z, Rui-Yong C, Xiang-Qun N, Xiao-Lan T, Yi L, Yan-Chao T. Hyperbaric oxygen therapy in an elderly critical coronavirus disease 2019 patient with endotracheal intubation: clinical effect analysis. Acad J Second Mil Med Univ. 2020;6:621-7.

31. Jiang B, Wei H. Oxygen therapy strategies and techniques to treat hypoxia in COVID-19 patients. Eur Rev Med Pharmacol Sci. 2020;24(19):10239-46.

32. Li G, Zhou X, Xu P, Pan X, Chen Y. Microstructure assessment of the thalamus in Wilson's disease using diffusion tensor imaging. Clin Radiol. 2014;69(3):294-8.

33. Schmidt M, Hajage D, Lebreton G, Monsel A, Voiriot G, Levy D, et al. Extracorporeal membrane oxygenation for severe acute respiratory distress syndrome associated with COVID-19: a retrospective cohort study. Lancet Respir Med. 2020;8(11):1121-31.

34. Barbaro RP, MacLaren G, Boonstra PS, Iwashyna TJ, Slutsky AS, Fan E, et al. Extracorporeal membrane oxygenation support in COVID-19: an international cohort study of the Extracorporeal Life Support Organization registry. Lancet. 2020;396(10257):1071-8.

35. Barrot L, Asfar P, Mauny F, Winiszewski H, Montini F, Badie J, et al. Liberal or conservative oxygen therapy for acute respiratory distress syndrome. N Engl J Med. 2020;382(11):999-1008.

36. Chu DK, Kim LH, Young PJ, Zamiri N, Almenawer SA, Jaeschke R, et al. Mortality and morbidity in acutely ill adults treated with liberal versus conservative oxygen therapy (IOTA): a systematic review and meta-analysis. Lancet. 2018;391(10131):1693-705.

37. Frat JP, Thille AW, Mercat A, Girault C, Ragot S, Perbet S, et al. High-flow oxygen through nasal cannula in acute hypoxemic respiratory failure. $\mathrm{N}$ Engl J Med. 2015;372(23):2185-96.

38. Ghiasvand F, SeyedAlinaghi S, Tirgar S, Salehi MR, Moradmand-Badie B. A patient with COVID-19 Pneumonia presenting with plural effusion: a case report. Infect Disord Drug Targets. 2020. https://doi.org/10.2174/18715 26520666201116095440.

39. Harch PG. Hyperbaric oxygen treatment of novel coronavirus (COVID-19) respiratory failure. Med Gas Res. 2020;10(2):61-2.

40. Kjellberg A, De Maio A, Lindholm P. Can hyperbaric oxygen safely serve as an anti-inflammatory treatment for COVID-19? Med Hypotheses. 2020;144:11022.

41. Heyboer M 3rd, Sharma D, Santiago W, McCulloch N. Hyperbaric oxygen therapy: side effects defined and quantified. Adv Wound Care (New Rochelle). 2017;6(6):210-24.

\section{Publisher's Note}

Springer Nature remains neutral with regard to jurisdictional claims in published maps and institutional affiliations. 